\title{
Evaluation of Genetic Fidelity among Two Different Cultivars of Gerbera (Gerbera jamesonii Bolus) Using DNA Based Molecular Marker RAPD
}

\author{
Jotshana Manik Maske*, Rajput Charansing Amarsing and Zote Rahul Keshavrao \\ Department of Plant BiotechnologySDMVM's College of Agricultural Biotechnology, \\ GeoraiTanda, Paithan Road, Aurangabad (M.S.)- 431001, India \\ *Corresponding author
}

\begin{tabular}{|l|}
\hline K e y w or d s \\
Genetic fidelity, \\
Gerbera, DNA, \\
RAPD \\
\hline Article Info \\
\hline $\begin{array}{l}\text { Accepted: } \\
\text { 25 May } 2018 \\
\text { Available Online: } \\
\text { 10 June } 2018\end{array}$ \\
\hline
\end{tabular}

\section{Keywords}

Genetic fidelity, Gerbera, DNA,

Article Info

Accepted:

25 May 2018

10 June 2018

\begin{abstract}
The present Study entitled "RAPD Based Evaluation of Genetic Fidelity of in vitro Propagated Gerbera (Gerbera jamesonii Bolus) Variety 1385 and 1201 " was carried out at carried out at Department of Plant Biotechnology SDMVM's College of Agricultural Biotechnology, Georai Tanda, Paithan Road, Aurangabad (M.S.), 431001. The present study has been planned to evaluate genetic fidelity among two different cultivars of gerbera using DNA based molecular marker RAPD with following objectives, DNA extraction from Gerbera varietes 1385 and 1201 and Evaluation of Genetic Fidelity in vitro Propagated Gerbera (Gerbera jamesonii Bolus) from Variety 1385 and 1201.The result of the present study clearly indicated that the varieties viz-1385 \& 1201 have shown monomorphic banding pattern with the primer OPA 19. The plantlet of both the varieties were also tested to see the genetic variation and it has been observed that the plantlet have also shown monomorphic banding with primer OPA19, Clearly indicating their homozygocity.
\end{abstract}

\section{Introduction}

Gerbera is an important commercial flower grown throughout the world. It is a perennial herb native to South Africa and Asia belongs to the family Asteraceae. Gerbera produces very attractive flowers in various colours and ranked among the top ten cut flowers. It is also called Transvaal daisy, Barberton daisy or African daisy. Beside as a cut flower, it is also very ideal for beds, borders, pots and rock gardens. However, somaclonal variation may arise due to the genetic or epigenetic changes. The latter being unstable and not transmitted to the progeny has to be identified before plants are multiplied for large-scale production using biochemical (isozymes) and molecular markers (RAPD, RFLP, and AFLP).

It is suggested that genetic engineering has yet to provide a cost effective and reliable products and moreover, unstable gene expression especially for flower colour is a 
major problem in transgenic plants under field conditions. For the unique planting material or true-to-type plant is necessary to gain the market value. Its need to assess the clonal fidelity of in vitro raised plant using different molecular techniques like DNA fingerprinting and marker analysis.

Polymerase chain reaction (PCR)-based techniques such as random amplified polymorphic DNA (RAPD) and inter simple sequence repeat (ISSR) are immensely useful in establishing the genetic stability of in vitroregenerated plantlets in many crop species (Lakshmanan et. al. 2007; Joshi and Dhawan, 2007).

RAPD and ISSR markers are very simple, fast, cost-effective, highly discriminative and reliable. They require only a small quantity of DNA sample and they do not need any prior sequence information to design the primer. They do not use radioactive probes as in restriction fragment length polymorphism (RFLP) (Lakshmanan et. al., 2007). Thus, they are suitable for the assessment of the genetic fidelity of in vitro raised clones.

The main advantage of random amplified polymorphic DNA (RAPD) markers over other molecular markers, in particular to markers involving DNA-DNA hybridization techniques, is the low technical input and small quantity of DNA needed for the analysis.

The present study has been planned to evaluate genetic fidelity among two different cultivars of gerbera using DNA based molecular marker RAPD with following objectives,

1) DNA extraction from Gerbera varietes 1385 and 1201. 2) Evaluation of Genetic Fidelity in vitro Propagated Gerbera (Gerbera jamesonii Bolus) from Variety 1385 and 1201.

\section{Materials and Methods}

The present Study entitled "RAPD Based Evaluation of Genetic Fidelity of in vitro Propagated Gerbera (Gerbera jamesonii Bolus) Variety 1385 and 1201" was carried out at carried out at Department of Plant Biotechnology SDMVM's College of Agricultural Biotechnology, Georai Tanda, Paithan Road, Aurangabad (M.S.), 431001. The details of the material used and methods followed for the present Study are below.

\section{Materials}

\section{Laboratory chemicals, glassware and plastic wares}

Chemicals used for the present study were of good quality (MB grade) from various agencies like Merck India Ltd., HIMEDIA and SISCO Research Laboratories. Details are as follows.

\section{Material}

Chemical Name: - Company

1) Agarose Lonzd

2) $\beta$-mercaptoethanol Hi media

3) Chloroform Merck

4) C-TAB (Cetyl- Trimethyl Ammonium Bromide) Sigma

5) dNTP Mix NEB

6) EDTA (Ethylene diamine Tetra Acetic Acid) Hi media

7) $\mathrm{EtBr}$ (Ethidium Bromide) Hi media

8) $70 \%$ Ethanol/ $95 \%$ EthanolOmnis

9) Glacial acetic acid Hi media

10) Iso amyl alcohol Qualigens

11) Iso-Propanol Rankem

12) Ladder Fermentes

13) 6x loading dye Fermentes

14) $\mathrm{NaCl}$ (Sodium Chloride) Hi media

15) $\mathrm{Na} / \mathrm{K}$ (Sodium/Potassium Acetate) Hi media 
16) PVP (Polyvinyl Pyrrolidone) Sigma Alorich

17) Primer

IDT

18) RNase

Hi media

19) Taq-polymerase

$\mathrm{GeNei}^{\mathrm{TM}}$

20) Tris Base

NEB

\section{Equipments}

The present research work was carried out using molecular biology facilities available at Bejo Sheetal Bioscience Foundation, Jalna. Centrifugation was done in High speed refrigerated centrifuge (KUBOTA 6500)/ Dynamic Velocity 14R Refrigerated Centrifuge.

Nano DropR ND-1000 spectrophotometer was used for the estimation of quality and quantity of DNA. DNA amplification reaction was carried out in Agilent Technologies thermocycler (BIORAD). Horizontal gel electrophoresis system (BIO-RAD, USA) was used for agarose gel electrophoresis. Gel Doc - (Alphalnnotech) was used for imaging and documenting the agarose gel profile.

\section{Source of explants}

Commercially released variety of gerbera from Montiplanta India Pvt. Ltd., viz., Var. 1385 and 1201 were used for the study. Details of flower character are provided in Table 1. Source mother plants were maintained in net house and in vitro culture of mother plant in growth room of Bejo Sheetal Bioscience Foundation, Jalna. The varieties with different flower colours (dark pink and whitish yellow) were included.

\section{Methodology}

Genetic fidelity studies using RAPD molecular marker

For evaluation of micropropagated plants mother plant, RAPD molecular assay was carried out. Mother plants and mother regenerates were subjected to genetic stability studies using RAPD assay with two RAPD primers reported for gerbera by Bhatia et al. 2010. The main advantage of RAPD markers is very simple, fast, cost-effective, highly discriminative and reliable. They require only a small quantity of DNA sample (50-150 ng per reaction) and they do not need any prior sequence information to design the primer. They do not use radioactive probes as in restriction fragment length polymorphism (RFLP) (Lakshmanan et al., 2007). RAPDs are randomly distributed throughout the genome. Thus, they are suitable for the evaluation of the genetic fidelity of in vitro regenerated plants.

\section{Molecular marker assay}

Random amplified polymorphic DNA (RAPD) was used for evaluation of genetic fidelity of mother and in vitro plantlets.

\section{Random amplified polymorphic DNA (RAPD) analysis}

Good quality genomic DNA (30 to $50 \mathrm{ng} / \mu \mathrm{l}$ ) isolated from gerbera mother plant samples and mother plant regenerated in vitro culture samples were subjected to RAPD assay. RAPD primer supplied by IDT with good resolving power was used for amplification of DNA.

\section{RAPD primers selected for the study}

Based on earlier reports on RAPD assay in gerbera by Bhatia et al (2010), two RAPD primers were selected for the study. Details of selected primers are presented in Table 2 . The selected primer was checked for amplification using bulked DNA from different groups of plants in the present study.

The amplification was carried out in an Agilent thermocycler. Amplification was 
performed in a $25 \mu$ reaction mixture as shown below:

Composition of the reaction mixture for PCR

\section{PCR reaction:}

\section{PCR reaction master mix reagent}

Components Quantity (In 1 sample) in $\mu 1$

1) $10 \mathrm{x}$ buffer $\quad 2.5$

2) dNTP $\quad 1.0$

3) Primers 2.5

4) Taq Polymerase $\quad 0.2$

5) Template DNA $\quad 0.5$

6) SDW

18.3

\section{TOTAL}

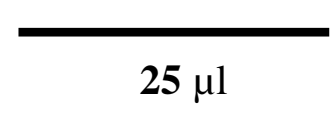

Data analysis

Scoring of RAPD amplified bands and genotyping

The banding patterns obtained from PCR amplification of the various RAPD primers in each of the genotype was visualized under silver UV transilluminater were scored as follow.

\section{Results and Discussion}

The results of the investigations on "RAPD Based Evaluation of Genetic Fidelity of in vitro Propagated Gerbera (Gerbera jamesonii Bolus) Variety 1385 and 1201" conducted at the Department of Plant Biotechnology SDMVM's College of Agricultural Biotechnology, Georai Tanda, Paithan Road, Aurangabad (M.S.), 431001 during the period December 2016 to March 2016 are presented in this chapter under different sub headings.

\section{Isolation and purification of DNA}

Genomic DNA isolated through CTAB method reported by Roger and Bendich (1994) was not pure and had slight RNA contamination. RNase treatment after DNA isolation resulted in good quality DNA (Fig. $1)$.

\section{Quantification of DNA}

The quality and quantity of isolated DNA was analyzed using both electrophoresis and NanoDrop spectrophotometer. Intact clear bands indicated that DNA extracted was nondegraded and was of good quality. Spectrophotometric analysis gave ratio of UV absorbance (A260/280) between 1.8 and 2.0. The DNA after appropriate dilution was used as template for RAPD analyses.

\section{RAPD analysis}

Gerbera specific RAPD primer reported by Bhatia et al (2010) was selected. The details of selected RAPD primer are given in Table 2.

Genomic DNA isolated from two sources viz., mother plants and in vitro regenerates from mother plant were subjected to RAPD analysis.

Mother plant and micro propagated of variety 1385 and 1201

The amplification pattern obtained for plants derived from mother plant of different subculturing cycle and mother plant of variety 1385 and1201 with specific selected RAPD primers is provided in Fig (2). Primer specific amplification details are as shown below:

\section{OPA-19 with var. 1385}

A total of five clear amplicons were obtained with the primer OPA-19. The pattern of amplification is showned in Fig.2 the molecular weight of amplicons ranged between 400 to $1200 \mathrm{bp}$. There was no polymorphic band observed in var. 1385 with primer OPA 19. DNA from two groups of 
plants produced monomorphic bands when resolved with the primer OPA-19.

\section{OPA-19 with var. 1201}

Amplification with the primer OPA-19in var. 1201generated six clear amplicons. The pattern of amplification is shown in Fig 2. The amplicons obtained with the primer were monomorphic. The molecular weight of amplicons ranged from 475 to $1250 \mathrm{bp}$.

\section{Amplification pattern in micropropagated plants of variety 1385 with RAPD primers}

In variety 1385, two groups of plants viz. mother plants and mother plant regenerants of different subculture cycle were compared using the selected OPA 19 primer. Both varieties were showed the genetically similarity in respected derived in vitro plantlets from source plants. But in both the varieties some degree variation observed at DNA leval. It might be regarding flower colour or any other traits.

In the present study, PCR-based technique, RAPD was adopted to characterize the in vitro regenerants. RAPD primer reported by Bhatia et al., (2010) were selected for the study. Genomic DNA isolated from various sources viz., mother plants, regenerates from mother plant of different sub culturing cycle were subjected to RAPD analysis. Two groups of plants of the variety 1385 and 1201 viz. mother plant, mother plant regenernts were subjected to RAPD assay. OPA-19 primer tested, it gave monomorphic amplicons.

Table.1 Details of gerbera varieties

\begin{tabular}{|l|l|l|}
\hline Description & Variety & $\mathbf{1 2 0 1}$ \\
\hline & $\mathbf{1 3 8 5}$ & $12 \mathrm{~cm}$ \\
\hline Diameter & $12 \mathrm{~cm}$ & $65 \mathrm{~cm}$ \\
\hline Stem length & $65 \mathrm{~cm}$ & 16 day \\
\hline Vase life & 16 day & Whitish yellow \\
\hline Colour & Dark pink & Double \\
\hline Flower type & Double &
\end{tabular}

Table.2 Details of Primers:

\begin{tabular}{|l|l|l|l|}
\hline Sr. No & Primer code & \multicolumn{1}{|c|}{ Sequence 5'-3' } & Annealing temp. \\
\hline 1 & OPA-19 & 5'CAAACGTCGG3' & $36{ }^{\circ} \mathrm{C}$ \\
\hline
\end{tabular}

Fig.1 Quantification of DNA

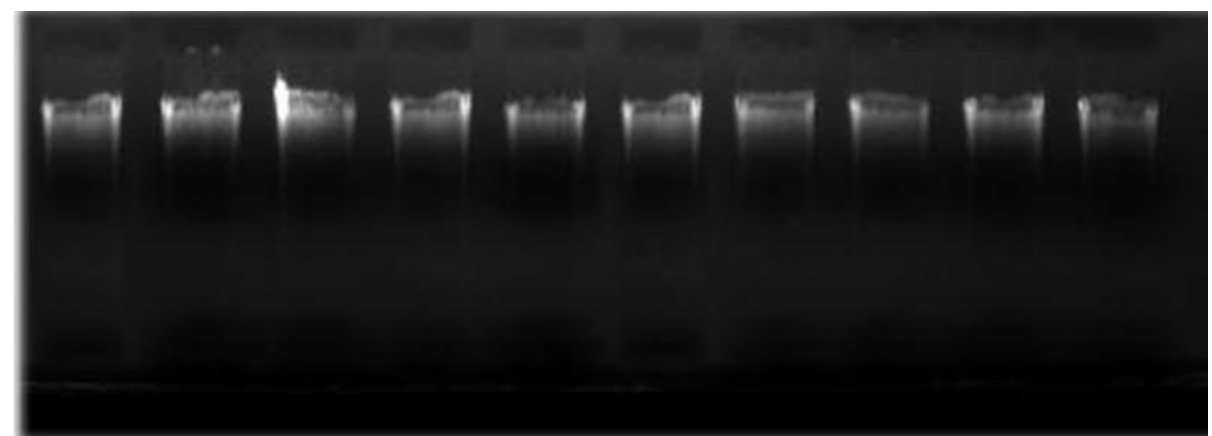

1: Mother plant of var. 1385, 2 -5: in vitro regenerants from different subcultring cycle of var. 1385, 6: Mother plant of var. 1201, 7-10: in vitro regenerants from different subcultring cycle of var. 1201 
Fig.2 Amplification pattern of var. 1385 and 1201with RAPD primer OPA 19

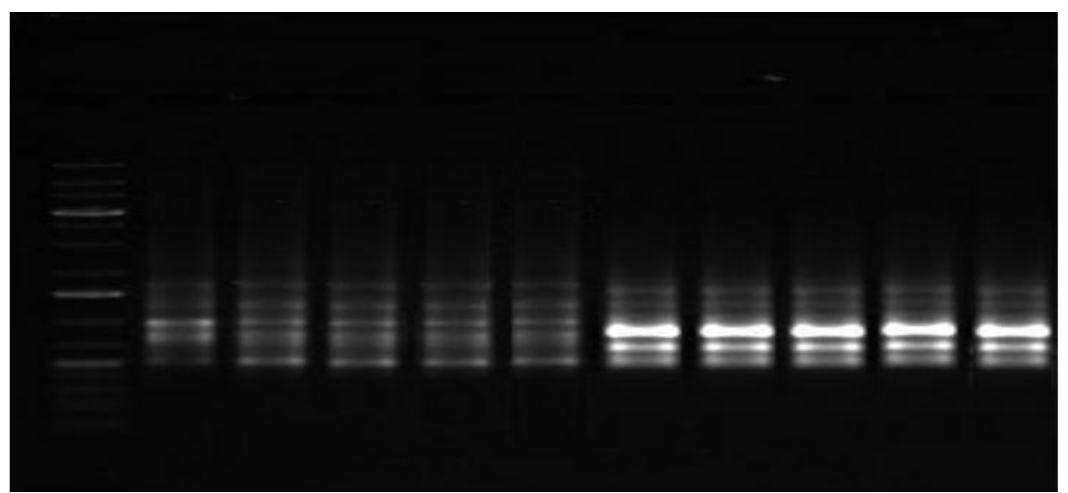

L: ladder, 1: Mother plant of var. 1385, 2 -5: in vitro regenerants from different subcultring cycle of var. 1385, 6: Mother plant of var. 1201, 7-10: in vitro regenerants from different subcultring cycle of var. 1201

In the previous studies it was reported that the presence or absence of variations during in vitro propagation depends upon the source of explants and the method of regeneration (Goto et al. 1998). The sub- and supraoptimal levels of plant growth substances, especially synthetic ones, have also been associated with somaclonal variation (Martin et al., 2004). Even at optimal levels, longterm multiplication and high chromosome number of the plant may often lead to somaclonal or epigenetic variations in micropropagated plants, thus, questioning the varies fidelity of their clonal nature. In present study, plantlets were obtained from both groups variation at DNA level was not observed. Both groups were genetically similar to each other.

In some reports, plants derived from organized meristems are not always genetically true-to-the type in many crops (Devarumath et al., 2002). Plants regenerated from adventitious shoots from axillary buds or from other well developed meristematic tissue showed the lowest tendency for genetic variation (Joshi and Dhawan, 2007). Hence, it becomes imperative to regularly check the genetic purity of the micropropagated plants in order to produce clonally uniform progeny while using different techniques of micropropagation
Joshi and Dhawan (2007) have employed ISSR marker assay to validate the genetic fidelity of Swertiachirayitaplantlets multiplied in vitro by axillary multiplication up to forty-two passages. Gantait et al. (2010) reported the clonal fidelity of micropropagated and sustained cultured clones of Allium ampeloprasumL. using ISSR primers.

Bhatia et al. (2010) reported genetic fidelity of in vitro raised plants of gerbera derived from three different explants viz., capitulum, leaf and shoot tips using ISSR assay. The clones derived from capitulum and shoot tip explants did not show any genetic variation. Similar results are found in present study also, here micropropagated plantlets derived from mother plant shown genetically similar with RAPD primer OPA-19.

The genetic fidelity of in vitro-raised gerbera derived from capitulum explants was assessed by using RAPD and ISSR markers (Bhatia $e t$ al., 2011). In another report by Borse et al. (2011) clonal fidelity of banana (Musa acuminatacv. Grand Naine) regenerants from six different in vitro subculture generations and in the explant suckers were evaluated by using ISSR and REMAP molecular markers. Very low variation was observed up to the 
eighth subculture generations with polymorphic bands both ISSR $(0.96 \%)$ and REMAP $(0.95 \%)$ markers system. But present investigation is not agreed to given results.

Parida et al. (2011) assessed genetic fidelity of in vitro regenerated AlpiniagalangaL. subjected to RAPD and ISSR markers to assess genetic stability. Nadha et al. (2011) were confirmed the true-to-type nature of the in vitro raised clones of $G$. angustifoliaKunth using RAPD and ISSR markers for variability in the tissue culture raised plantlets. Khateeb et al. (2013) assessed genetic stability of micropropagated plants of Moringaperegrinausing ISSR. In all reported studies, they found the monomorphic amplification in different explants regenerants and ensured true-to-type nature of micropropagated plants. In present study also found similar result and agreed to their results.

Majority of the gerbera specific primers exhibited monomorphic banding pattern both in plants regenerated from mother plant and source plant which showed their uniformity. OPA-19 primers tested in two groups of plants in variety 1201 and 1385 (mother plant, regenerants), OPA-19 primer exhibited monomorphic banding pattern.

However, thorough phenotypic evaluation of the micropropagated plants is to be undertaken to know the variation if any in flower morphology and other floral characters before recommending the protocol for commercial micropropagation.

The result of the present study clearly concluded that the varieties viz-1385 and 1201 have shown monomorphic banding pattern with the primer OPA 19 . The plantlet of both the varieties were also tested to see the genetic variation and it has been observed that the plantlet have also shown monomorphic banding with primer OPA19, Clearly indicating their homozygocity.

\section{References}

Bhatia R, K.P Singh, T.R. Sharma, Tripta Jhang 2011. Evaluation of the genetic fidelity of In vitro propagated gerbera (Gerbera jamesonii Bolus using DNA- based markers. Plant Cell Tiss. Organ Cult.104:131-135. DOI10.1007/s11240-010-9806-5.

Bhatia R. P., Singh T., R. Sharma, Tripta Jhang (2010). Evaluation of the genetic fidelity of in vitro-propagated gerbera (Gerbera jamesonii Bolus) using DNA-based markers. Springer Science Business Media B.V. Plant Cell Tiss Organ Cult DOI 10.1007/s11240-010-9806-5.

Bhorse N., Vivek. A. P. Chimote A. and Jadhav S 2011. clonal fidelity of banana (Musa acuminatacv, var. Grand Nine) regenerants from six different in vitro subculture generations and in the explant suckers were evaluated by using ISSR and REMAP molecular markers.ScientiHorticuiture 129:390395.

Codd, L.E. (1979) the story of the Barberton daisy, gerbera jamesonii. veld and flora (December), 114-115.

Devarumath R. M., Nandy S., Rani V., MarimuthuS.andMuraleedharan N. 2002. RAPD, ISSR and RFLP fingerprints as useful markers to evaluate genetic integrity of micropropagated plants of three diploid and triploid elite tea clones representing Camellia sinensis(China type) and $C$. assamica $s p$. Assamica(Assam- India type). Plant Cell Rep. 21:166-173.

Gantait S, Mandal N. Somanath Bhattacharyya., and P. Kanti Das 
2010.Determination Of Genetics Intigrity In Long Term Micropopagated Plants Of Allium Ampeloprasum L. Using ISSR Marker Article In Biotechnology 9(2) Feb 2010 Dol 10:3923/2010-218-223.

Goto S., Thakur R. C. and Ishii K. (1998). Determination of genetic stability in long-term micropropagated shoots of PinusthunbergiiParl. using RAPD markers. Plant Cell Rep. 18:193-197.

Joshi P. and Dhawan V. 2007. Assessment of genetic fidelity of micro propagated Swertiachirayita plantlets by ISSR marker assay. Biol. Plant. 51:22-26

Khateeb WA, Bahar E, Lahham J, Schroeder D, Hussein E (2013) Regeneration and assessment of genetic fidelity of the endangered tree Moringa peregrina (Forsk.) Fiori using inter simple sequence repeat (ISSR). Physiol Mol Biol Plants 19(1): 157-164.

Lakshmanan V., Venkataramareddy S. R.andNeelwarne B. 2007. Molecular analysis of genetic stability in longterm micro propagated shoots of banana using RAPD and ISSR markers. Electron J. Biotech. 10:1-8.

Martin M., Sarmento D. and Oliveira M. M. 2004.Genetic stability of micropropagated almond plantlets, as assessed by RAPD and ISSR markers.Plant Cell Rep. 23:492-496.

Murashige, T., Serpa, M. and Jones, J.B (1974): clonal multiplication through tissue culture. Hort science, 9:175180.

Nadha H. K., Kumar R., Sharma R. K., Anand M., Sood A. 2011. Evaluation Of Clonal Fidelity Of In Vitro Raised Plants OfguaduaAngustifolia Kunth Using DNA-Based Markers. J Med Plants Res. 2011;5(23):5636-5641.

Parida R, Mohanty S, Nayak S (2011) Evaluation of genetic fidelity of in vitro propagated greater galangal (alpinia galanga 1.) using DNA based markers. International Journal of Plant, Animal and Environmental Sciences 1(3): 123 - 133.

Pierik, R. L.M., Segers, and H.H. M., 1973: In vitro culture of midrib explants of gerbera. Adventitious formation and callus induction. Z. Pflanzenphysiol. 69, 204-12.

Rogers and Arnold J. Bendich (1994): Extraction of total cellular DNA from plant, algae and fungi. Plant Molecular Biology Manual D1: 1-8.

Sambrook, J. E. F. Frisch and T. Maniatis, (1989): The DNA isolated would contain RNA as contaminant and was hence purified by treatment with RNase and further precipitated. pp. 95-120. (Cold Spring Harbor Laboratory, New York).

Schiva T., 1975: Vegetative propagation in gerbera improvement. Annalidell' Instituto Sperimentale perla Floricultura, 6: 133- 135.

\section{How to cite this article:}

Jotshana Manik Maske, Rajput Charansing Amarsing and Zote Rahul Keshavrao. 2018. Evaluation of Genetic Fidelity among Two Different Cultivars of Gerbera (Gerbera jamesonii Bolus) Using DNA Based Molecular Marker RAPD. Int.J.Curr.Microbiol.App.Sci. 7(06): 3551-3558. doi: https://doi.org/10.20546/ijcmas.2018.706.417 